\title{
Kan psykiatrisk akutteam redusere bruk av akuttplasser ved sykehus?
}

\begin{abstract}
Sammendrag
Bakgrunn. Akutteam som alternativ til innleggelse i psykiatrisk akuttavdeling er innført i Norge ut fra positive erfaringer $i$ andre land. Det foreligger ingen undersøkelse om effekten av akutteam i Norge. Notodden/Seljord DPS opprettet et akutteam i januar 2004 for en del av sitt opptaksområde lopptaksområde 1).
\end{abstract}

Materiale og metode. Materialet består av informasjon om de pasientene som ble innlagt i psykiatrisk akuttavdeling ved Sykehuset Telemark i 2003 og 2004 fra opptaksområde 1 med akutteam og opptaksområde 2 uten akutteam, samt akutteamets pasienter i 2004.

Resultater. I 2004 var det en reduksjon av innleggelser ved psykiatrisk akuttavdeling ved Sykehuset Telemark på $25 \%$ fra opptaksområde 1 mot $13 \%$ fra opptaksområde 2 sammenliknet med 2003. Akutteamet behandlet 22 pasienter, hvorav fem ble innlagt i distriktspsykiatrisk senter. Pasienter med psykose eller alvorlig depresjon ble i hovedsak innlagt i psykiatrisk akuttavdeling.

Fortolkning. Akutteam ved godt bemannet distriktspsykiatrisk senter kan bidra til mindre bruk av psykiatrisk akuttavdeling ved å fange opp pasienter med moderat alvorlige lidelser, mens pasientene med de alvorligste lidelsene fortsatt blir innlagt $i$ akuttavdelingen.

\section{Ole-Bjørn Kolbjørnsrud}

ole-bjorn.kolbjornsrud@sthf.no

Notodden/Seljord DPS

Henrik Wergelands gate 9

3675 Notodden

\section{Frode Larsen}

Psykiatrisk divisjon

Oslo universitetssykehus, Ullevål

Guro Elbert

FoU

Blefjell sykehus

\section{Torleif Ruud}

Avdeling for psykisk helsevern

Akershus universitetssykehus og

Institutt for psykiatri

Universitetet i Oslo

Behandling ved psykiatriske akutteam prøves nå ut her i landet som et alternativ til behandling i psykiatrisk akuttavdeling. Inspirasjonen og modellen for dette er hentet fra Storbritannia, der det også har vært utført noe forsking om alternative akuttpsykiatriske tilbud $(1,2)$. I en Cochrane-oversikt har man oppsummert slike undersøkelser (3), og i en norsk oversiktsartikkel har man særlig tatt for seg studier om akutteam (4). To britiske undersøkelser har vist at ambulante akutteam kan redusere antall innleggelser $\mathrm{i}$ psykiatriske akuttavdelinger $(5,6)$. Dette støttes av en landsomfattende undersøkelse om forskjeller mellom områder med og uten akutteam (7).

I Norge har statlige helsemyndigheter besluttet at akutteam med øyeblikkelig hjelpfunksjon skal utprøves og etableres ved alle distriktspsykiatriske sentre innen utgangen av $2008(8,9)$, og slike team etableres nå derfor ved stadig flere distriktspsykiatriske sentre. Det har ikke vært noen omfattende faglig høring forut for denne beslutningen. Det er stor variasjon mellom team når det gjelder bemanning, oppgaver, forhold til kommunehelsetjenesten og disponering av kriseplasser. Mens akutteamene i Storbritannia er tilgjengelige 24 timer i døgnet hele uken, arbeider de fleste akutteam i Norge bare på dagtid eller arbeidstiden er utvidet med noen timer på kveldstid og i helger. Det er derfor usikkert i hvilken grad teamene i Norge vil ha samme effekt som teamene i Storbritannia. Det er ikke publisert norske studier om i hvilken grad akutteam bidrar til å redusere innleggelsene ved psykiatriske akuttavdelinger.

Notodden/Seljord DPS har ansvaret for det psykiatriske lokalsykehustilbudet for 45000 innbyggere i 11 kommuner i øvre Telemark. Senteret, som har en poliklinikk og en døgn- og dagavdeling både på Not- odden og i Seljord, er godt bemannet med de fleste aktuelle faggrupper. Vi har 95 stillinger, inkludert seks overleger og fire assistentleger. Døgnavdelingene har hver sin overlege tilknyttet i full stilling og er spesialisert $i$ forhold til type og alvorlighetsgrad av psykisk lidelse som skal behandles. Senteret har vaktordning med spesialist på døgnbasis.

Det lokale psykiatriske tilbudet ved akutte kriser har likevel ikke vært tilfredsstillende. Den psykiatriske akuttavdelingen ved Sykehuset Telemark har vært betydelig presset og har i lengre perioder hatt overbelegg. Våre psykiatriske poliklinikker organiserer virksomheten slik at en person har satt av noe tid hver dag i ukens fem første dager til kriseintervensjon. Dette tilbudet har heller ikke vært tilstrekkelig i de tilfeller der situasjonen krever mer rask og omfattende kartlegging eller intervensjon fra flere instanser.

\section{Akutteam som alternativ til innleggelse}

Med bakgrunn i at vi ønsket å forbedre vår akuttservice, opprettet vi 1.1. 2004 et akuttteam ved Notodden/Seljord DPS, avdeling Notodden. Hensikten med teamet var å redusere antall innleggelser ved akuttpsykiatrisk avdeling, Sykehuset Telemark ved å gi et raskt og tilstrekkelig omfattende lokalt akuttilbud ved et team som kunne reise ut i kommunen og hjem til pasienten. Ved god tilgjengelighet ønsket vi å komme tidlig til i sykdomsforløpet, slik at antall innleggelser $i$ akuttavdeling ved sentralsykehuset kunne reduseres. En del av innleggelsene ved psykiatrisk akuttavdeling, Sykehuset Telemark skjer på kveldstid. Om primærlegene kjente til akutteamets tilbud, kunne trolig en del pasienter bli henvist til akutteamet dagen etter i stedet for å bli innlagt i akuttavdelingen på kveldstid.

Teamet består av en lege og tre psykiatriske sykepleiere som organiserer arbeidet slik at to av disse kan rykke ut på dagtid de

\section{Hovedbudskap}

- Storsatsingen på psykiatriske akutteam i Norge er ikke evaluert

- Vi fant ingen signifikant reduksjon av akuttinnleggelser fra område med psykiatrisk akutteam

- Akutteamet hadde særlig pasienter med ikke-psykotiske kriser

- Man bør undersøke effekten av akuttteam med økt åpningstid og bemanning 
første fem dagene i uken. Henvendelsene må komme til poliklinikken før ordinær arbeidstid er slutt kl 1530, men teamets arbeidsdag vil ved utrykning kunne vare til ca. kl 19. Legen er teamleder og er disponibel for teamet hver dag. Alle i teamet arbeider til daglig ved allmennpsykiatrisk døgnpost på Notodden, men de vil kunne «slippe det de har $\mathrm{i}$ hendene» og rykke ut innen to timer.

Primærlegen definerer hva som er en akutt sak. Dersom legen mener at det er behov for rask hjelp fra den psykiatriske spesialisthelsetjenesten, at konsultasjon ved psykiatrisk poliklinikk ikke er tilstrekkelig og at rask innleggelse vil være aktuelt, er dette en oppgave for akutteamet.

Teamet skal kartlegge situasjonen, håndtere den akutte krisen og sørge for videre nødvendig utredning og behandling og oppfølging av pasienten og ev. familie. Det er ønskelig at representant fra den kommunale psykiatritjenesten deltar sammen med akutteamet på dette dersom det er praktisk mulig. Teamet skal vektlegge familie- og nettverksperspektivet, og det skal sammenkalle til nettverksmøte innen 24 timer der dette er hensiktsmessig. Etter en bred evaluering vil det bli avgjort hvilke tiltak som skal settes inn videre. Dette kan være oppfølging ved poliklinikken, hjemmebesøk ved teamet en eller flere ganger i løpet av de nærmeste to ukene, innleggelse på åpen døgnavdeling ved distriktspsykiatrisk senter eller innleggelse i akuttavdelingen ved Sykehuset Telemark.

\section{Hypotese og problemstillinger}

Hypotesen for undersøkelsen var at det fra kommunene med tilgang på akutteam i 2004 ville bli færre akuttinnleggelser og ev. færre tvangsinnleggelser ved psykiatrisk akuttavdeling ved Sykehuset Telemark i 2004 sammenliknet med samme område i 2003, og sammenliknet med kommunene uten akuttteam både i 2003 og 2004. Vi ville også undersøke diagnose, symptomnivå og funksjonsnivå for akutteamets pasienter sett i forhold til pasienter som ble innlagt i psykiatrisk akuttavdeling, Sykehuset Telemark. I tillegg ville vi undersøke hva som kjennetegnet akutteamets pasienter når det gjaldt kjønn, alder, psykiatriske problemer og rusmiddelmisbruk.

\section{Materiale og metode}

\section{Generell utforming}

Prosjektet er en kvasieksperimentell undersøkelse der noen kommuner får hjelp fra et

Tabell 1 Innleggelser ved de to opptaksområdene i 2003 og 2004

\begin{tabular}{|c|c|c|c|c|}
\hline & \multicolumn{2}{|c|}{ Område $1^{1}$} & \multicolumn{2}{|c|}{ Område $2^{2}$} \\
\hline & Antall & Per 100000 & Antall & Per 100000 \\
\hline \multicolumn{5}{|c|}{ Innleggelser } \\
\hline 2003 & 81 & 326 & 69 & 347 \\
\hline 2004 & 61 & 246 & 60 & 302 \\
\hline \multirow[t]{3}{*}{ P-verdi } & \multicolumn{2}{|c|}{0,09} & \multicolumn{2}{|c|}{0,43} \\
\hline & \multicolumn{2}{|c|}{ Område $1^{1}$} & \multicolumn{2}{|c|}{ Område $2^{2}$} \\
\hline & Antall & Per 100000 & Antall & Per 100000 \\
\hline \multicolumn{5}{|c|}{ Tvangsinnleggelser } \\
\hline 2003 & 51 & 205 & 36 & 181 \\
\hline 2004 & 39 & 157 & 30 & 151 \\
\hline P-verdi & \multicolumn{2}{|c|}{0,20} & \multicolumn{2}{|c|}{0,46} \\
\hline
\end{tabular}

Tabell 2 Hoveddiagnosegruppe i 2004 etter ICD-10

\begin{tabular}{|c|c|c|c|c|c|c|}
\hline & \multicolumn{2}{|c|}{$\begin{array}{l}\text { Akutteamets } \\
\text { pasienter } \\
(\mathrm{n}=22)\end{array}$} & \multicolumn{2}{|c|}{$\begin{array}{l}\text { Innlagt i Syke- } \\
\text { huset Telemark } \\
\text { fra område } 1 \\
\text { (n=61) }\end{array}$} & \multicolumn{2}{|c|}{$\begin{array}{l}\text { Innlagt i Syke- } \\
\text { huset Telemark } \\
\text { fra område } 2 \\
\text { (n=60) }\end{array}$} \\
\hline & Antall & $(\%)$ & Antall & $(\%)$ & Antall & {$[\%]$} \\
\hline Rusmiddelproblem & 3 & $(13,6)$ & 14 & $(23,0)$ & 5 & $(8,3)$ \\
\hline $\begin{array}{l}\text { Schizofreni og andre psykoser + } \\
\text { psykotiske stemningslidelser }\end{array}$ & 4 & $(18,3)$ & 23 & $(37,6)$ & 14 & $(23,3)$ \\
\hline Ikke-psykotiske stemningslidelser & 3 & $(13,6)$ & 10 & $(16,4)$ & 19 & $(31,7)$ \\
\hline Angstlidelser, nevroser & 3 & $(13,6)$ & 4 & $(6,6)$ & 9 & $(15,0)$ \\
\hline Spiseforstyrrelser & 1 & $(4,5)$ & & & & \\
\hline Personlighetsforstyrrelser & 6 & $(27,3)$ & 1 & $(1,6)$ & 7 & $(11,7)$ \\
\hline Andre & 2 & $(9,1)$ & 9 & $(14,7)$ & 6 & $(10,0)$ \\
\hline
\end{tabular}

akutteam, mens de andre kommunene får hjelp som er uforandret i forhold til dagens tilbud. Dette er gjennomført ved at opptaksområdet for Notodden/Seljord DPS deles i to. Kommunene som får tjenester fra voksenpsykiatrisk poliklinikk på Notodden (Notodden, Tinn, Sauherad og Hjartdal), kalles opptaksområde 1. For dette området med 24822 innbyggere ble det opprettet et akutteam. Kommunene som får tjenester fra voksenpsykiatrisk poliklinikk i Seljord (Seljord, Bø, Kviteseid, Tokke, Vinje, Nissedal og Fyresdal), kalles opptaksområde 2. Det har 19891 innbyggere og fikk ikke noe akutteam. Erfaringene fra en studie i Storbritannia om hvor komplisert det er å gjennomføre randomisering av akutte henvendelser (6), gjorde at vi ikke så noen mulighet for å gjennomføre en randomisert, kontrollert studie innen de rammene vi hadde.

De andre tilbudene ved distriktspsykiatrisk senter og sykehus er de samme for de to opptaksområdene. Dette gjelder henvisning til psykiatrisk poliklinikk i henholdsvis Notodden og Seljord, innleggelse på en døgnavdeling ved Notodden/Seljord DPS og innleggelse i akuttavdeling ved Sykehuset Telemark. Ved begge poliklinikkene har en terapeut satt av en time hver dag for å bistå primærlegene i akutte situasjoner ved å gi råd på telefon, ta imot pasienten for undersøkelse ved poliklinikken, gi noe oppfølging de nærmeste dagene, og samarbeide om innleggelse ved døgnavdeling ved behov for det.

\section{Materiale}

Materialet består av informasjon om de pasientene som ble innlagt i psykiatrisk akuttavdeling ved Sykehuset Telemark $\mathrm{i}$ året 2003 og 2004 fra opptaksområdene 1 og 2, samt de pasientene akutteamet hadde i 2004. For alle pasientene er det registrert kjønn, alder, innleggelser, om det er tvangsinnleggelse, diagnose (ICD-10), symptomnivå målt ved GAF-symptomskala og funksjonsnivå målt ved GAF-funksjonsskala (Global Assessment of Functioning Scale - splittet versjon) (10).

For akutteamets pasienter er det i tillegg registrert alvorlighetsgrad innen ulike problemområder ved HoNOS (Health of the Nation Outcome Scales) (11) og bruk av rusmidler (12). HoNOS skåres på en femtrinnsskala fra 0 (ikke problemer) til 4 (problemer i alvorlig til svært alvorlig grad). Personalet ved Notodden/Seljord DPS har gjennomgått systematisk opplæring i bruk av GAF og HoNOS.

Statistiske analyser er gjort ved khikvadrattest, Fishers eksakte test og variansanalyse i SPSS versjon 14.

\section{Resultater}

Innleggelser og tvangsinnleggelser i akuttavdeling

Antall innleggelser og tvangsinnleggelser fra de to opptaktsområdene i 2003 og 2004 er vist $\mathrm{i}$ tabell 1. I 2004 var det en nedgang $\mathrm{i}$ antall innleggelser fra kommunene $\mathrm{i}$ opp- 
taksområdet til Notodden/Seljord DPS ved psykiatrisk akuttavdeling, Sykehuset Telemark. Fra opptaksområde 1 med akutteam var reduksjonen $25 \%$, og fra opptaksområde 2 uten akutteam var reduksjonen $13 \%$. Antallet tvangsinnleggelser ble redusert med $12(24 \%)$ fra opptaksområde 1 og seks (17\%) fra opptaksområde 2. Andelen av tvangsinnleggelser økte fra $58 \%$ til $64 \%$ fra opptaksområde 1, mens andelen tvangsinnleggelser fra opptaksområde 2 var uforandret. Ingen av forskjellene var statistisk signifikante.

Forskjellen i demografiske variabler mellom pasientene i opptaksområde 1 og 2 var ubetydelig, bortsett fra kjønnsfordelingen med $57 \%$ kvinner i opptaksområde 1 og $43 \%$ i opptaksområde 2 . Forskjellen er ikke statistisk signifikant ( $p=0,14$ med Fishers eksakte test). Gjennomsnittsalder for hele materialet var 42 år (SD 16). Aldersfordelingen på pasientene $\mathrm{i}$ opptaksområdene var tilnærmet lik.

\section{Diagnostisk fordeling}

Fordeling av hoveddiagnoser i intervensjonsperioden fremgår av tabell 2. Pasienter med personlighetsforstyrrelser var overrepresentert blant akutteamets pasienter, mens pasienter som ble lagt inn i psykiatrisk akuttavdeling hyppigere led av psykoser og alvorlige depresjoner uten psykose. Nær $12 \%$ av pasientene innlagt i Sykehuset Telemark fra opptaksområde 2 hadde personlighetsforstyrrelse, mens kun $2 \%$ fra opptaksområde 1 hadde denne diagnosen. Opptaksområde 1 hadde større andel pasienter med rusproblemer innlagt i akuttavdelingen.

\section{Tilstandens alvorlighetsgrad}

GAF-skår for symptomnivå var i gjennomsnitt 36 (SD 13) for pasienter innlagt i akuttavdelingen fra opptaksområde 1 og 38 (SD 12) for pasienter innlagt fra opptaksområde 2. Tilsvarende GAF-skårer for funksjonsnivå var henholdsvis 39 (SD 15) og 38 (SD 13) for opptaksområde 1 og 2. Dersom pasienten er psykotisk, skal GAFsymptomnivå skåres <40. Det var $62 \%$ med GAF-symptomskår $<40$ fra opptaksområde 1 og $47 \%$ fra opptaksområde $2, \mathrm{og}$ denne forskjellen var statistisk signifikant $(\mathrm{p}<0,05)$. Det var ingen signifikant forskjell på de to opptaksområdene for andel pasienter med skår under 40 på GAF-funksjonsnivå.

\section{Akutteamets pasienter}

Akutteamet tok hånd om 22 pasienter. Ingen av dem ble innlagt i akuttpsykiatrisk avdeling ved Sykehuset Telemark. Men fem av pasientene ble innlagt $\mathrm{i}$ åpen døgnavdeling ved distriktspsykiatrisk senter. $32 \%$ var kvinner. Gjennomsnittsalderen var 35,7 år (SD 11) for kvinner og 45,5 år (SD 20 ) for menn. $78 \%$ hadde trygd som hovedinntektskilde (alders-/uføre-/attføringstrygd/ arbeidsledig), $36 \%$ var gift/samboende,

Tabell 3 Kliniske kjennetegn ved akutteamets pasienter

\begin{tabular}{|lccccc|} 
& \multicolumn{2}{c}{ Ikke/lite/mild grad } & \multicolumn{3}{c}{ Alvorlig grad } \\
\cline { 2 - 3 } \cline { 5 - 6 } HoNOS-skalaer & Antall & $(\%)$ & & Antall & $(\%)$ \\
\hline Agitasjon, aggresjon & 15 & $(68)$ & 7 & $(32)$ \\
\hline Selvskade & 17 & $(77)$ & 5 & $(23)$ \\
\hline Rusproblem & 18 & $(82)$ & 4 & $(18)$ \\
\hline Hallusinasjoner/vrangforestillinger & 16 & $(73)$ & 6 & $(27)$ \\
\hline Depresjon & 15 & $(68)$ & 7 & $(32)$ \\
\hline Angst & 10 & $(45)$ & 12 & $(55)$ \\
\hline Problem i forhold til andre & 10 & $(45)$ & 12 & $(55)$ \\
\hline & Avhold/ikke misbruk & Misbruk/avhengighet \\
\hline Bruk av rusmidler ${ }^{2}$ & Antall & $(\%)$ & Antall & $(\%)$ \\
\hline Alkohol & 18 & $(82)$ & 4 & $(18)$ \\
\hline Stoff/medikamenter & 17 & $(77)$ & 5 & $(23)$ \\
\hline
\end{tabular}

1 |kke/mild grad er skår 0-2, alvorlig grad er skår 3-4

${ }^{2}$ Avhold/ikke misbruk er skår 1-2, Misbruk/avhengighet er skår 3-5

$41 \%$ var enslige og $23 \%$ var skilt/separert. Halvparten hadde tidligere vært innlagt i psykiatrisk akuttavdeling ved Sykehuset Telemark.

Av de fem pasientene som ble innlagt ved døgnavdeling i distriktspsykiatrisk senter, var to kvinner og tre menn. Tre pasienter bodde alene. To pasienter hadde GAF-skår for symptomnivå og for funksjonsnivå $<40$. To pasienter hadde psykotisk lidelse, to hadde ikke-psykotisk depresjon og en pasient hadde konversjonstilstand og personlighetsforstyrrelse. Tre hadde tidligere vært innlagt i psykiatrisk akuttavdeling ved Sykehuset Telemark.

Skåringene på HoNOS for ulike problemområder hos akutteamets pasienter er vist $i$ tabell 3. Angst og problemer i forholdet til andre dominerte symptombildet. Samme tabell viser også omfanget av rusmiddelmisbruk.

\section{Diskusjon}

Antall innleggelser i akuttavdeling ved Sykehuset Telemark fra opptaksområde 1 ble redusert med $25 \%$ fra 2003 til 2004, mens reduksjonen for opptaksområde 2 var $13 \%$. Reduksjonen er altså større i opptaksområdet som har akutteam, men den påviste endringen er ikke statistisk signifikant. Dette samsvarer med funn fra en kvasieksperimentell undersøkelse i England der andelen av akutthenvendelsene som endte med innleggelse $\mathrm{i}$ akuttavdeling innen seks uker, ble redusert fra $71 \%$ til $49 \%$ etter etablering at et akutteam (5). I en randomisert klinisk studie utført av samme forskergruppe fant man at $22 \%$ av pasientene randomisert til akutteam ble innlagt i psykiatrisk avdeling mot $59 \%$ av pasientene som ikke hadde tilbud om akutteam, og denne forskjellen var signifikant (6). Ingen av de to engelske undersøkelsene viste noen signifikant reduksjon i tvangsinnleggelser, noe som også samsvarer med vår undersøkelse.
Forskjellen i endring i akuttinnleggelser mellom opptaksområde 1 og opptaksområde 2 kan skyldes akutteamets funksjon. Flere fastleger har gitt uttrykk for at de har unnlatt å legge inn akuttpasienter på kvelden når de vet at de kan få hjelp fra akutteamet neste morgen. Vi kjenner ikke til andre endringer i primærhelsetjenesten i opptaksområde 1 og 2 som skulle kunne forklare forskjellene i antall innleggelser i psykiatrisk sykehusavdeling.

Antall tvangsinnleggelser ble redusert i begge opptaksområdene, mens andelen tvangsinnleggelser fra opptaksområde 1 økte noe. Dette er i tråd med de øvrige resultatene og i tråd med ønsket effekt av akutteamet, nemlig at andelen pasienter med alvorlige lidelser øker blant dem som legges inn fordi akutteamet behandler pasienter med mer moderate lidelser og reduserer det samlede antall innleggelser. Tilsvarende viser sammenlikningen med opptaksområde 2 (tabell 2) at andelen innlagte med psykose var større fra opptaksområde $1, \mathrm{og}$ at andelen med lav GAF-symptomskår var større fra opptaksområde 1 enn fra opptaksområde 2. Det at andelen med rusproblemer var høyere i opptaksområde 1, kan ha sammenheng med at opptaksområde 1 har to byer der rusproblemer er mer utbredt enn i landkommunene.

Symptombildet hos akutteamets pasienter var dominert av angst og atferdsforstyrrelser sammen med senket stemningsleie og aggresjon. De fleste pasientene hadde til dels alvorlige angstplager og problemfylte relasjoner $\mathrm{i}$ forholdet til familie eller nære pårørende. Dette representerer stort sett krisereaksjoner hos ikke-psykotiske personer. Tabell 2 tyder også på at akuttpasienter med personlighetsforstyrrelser ble tatt hånd om av akutteamet i opptaksområde 1 . Åtte av 22 pasienter misbrukte alkohol eller andre former for rusmidler.

Akutteamet behandlet 22 pasienter, mens 
antall innleggelser gikk ned med 20 i opptaksområde 1 og ni i opptaksområde 2. Dersom en kunne forvente samme nedgang $\mathrm{i}$ opptaksområde 1 uten akutteam som i opptaksområde 2, tyder dette på at akutteamet kanskje også gir akuttilbud til noen som ikke ville ha blitt innlagt, slik at de samlede akuttilbudet når flere pasienter.

Det er mulig at både antall pasienter behandlet av akutteam og reduksjonen av akuttinnleggelser blir større dersom akuttteamets åpningstid forlenges, og dersom tilbudet er enda bedre innarbeidet og kjent både blant primærleger og ved akuttavdelingen. Det kan også tenkes at en høyere legebemanning i teamet kunne føre til økt antallet henvisninger.

Det distriktspsykiatriske senteret har brukt begrenset med ressurser til akutteamfunksjonen. Teamet består av personer som til daglig arbeider ved døgnavdelingen. De er lett tilgjengelig for primærlegen ved behov. Teamet fikk overraskende få henvendelser fra primærlegene dette første året. Primærlegene har gitt uttrykk for at vissheten om god tilgjengelighet på akutthjelp fra det distriktspsykiatriske senteret på dagtid i seg selv har bidratt til at de takler flere akutt- og krisehenvendelser uten å henvise til spesialisthelsetjenesten.

\section{Konklusjon}

Vår undersøkelse kan tyde på at akutteam ved et godt bemannet distriktspsykiatrisk senter vil kunne bidra til redusert bruk av psykiatrisk akuttavdeling for ikke-psykotiske pasienter som er i krise. Det er behov for flere undersøkelser om den funksjon psykiatriske akutteam kan ha, og for å se om effekten av akutteam blir tydeligere om åpningstid eller bemanning økes.

Oppgitte interessekonflikter: Ingen

\section{Litteratur}

1. Burns T, Beadsmoore A, Bhat AV at al. A controlled trial of home-based acute psychiatric services. I: Clinical and social outcome. Br J Psychiatry 1993; 163: 49-54

2. Beck A, Croudace TJ, Singh $S$ et al. The Nottingham Acute Bed Study: alternatives to acute psychiatric care. Br J Psychiatry 1997; 170: 247-52.

3. Joy CB, Adams CE, Rice K Crisis intervention for people with severe mental illnesses. Cochrane Database Syst Rev 2006; nr. 4: CD001087. http:// mrw.interscience.wiley.com/cochrane/clsysrev/ articles/CD001087/frame.html (30.3.2009).
4. Gråwe RW, Ruud T, Biørngaard JH. Alternative akuttilbud i psykisk helsevern for voksne. Tidsskr Nor Lægeforen 2005; 125: 3265-8.

5. Johnson S, Nolan F. Hoult J et al. Outcomes of crises before and after introduction of a crisis resolution team. Br J Psychiatry 2005; 187: 68-75.

6. Johnson S, Nolan F, Pilling S et al. Randomised controlled trial of acute mental health care by a crisis resolution team: the north Islington crisis study. BMJ 2005; 331: 599-603.

7. Glover G, Arts G, Babu KS. Crisis resolution/home treatment teams and psychiatric admission rates in England. Br J Psychiatry 2006; 189: 441-5.

8. Ot.prp.nr. 1 (2004-2005). Statsbudsjettet for bud sjettåret 2005.

9. Distriktspsykiatriske sentre - med blikket vendt mot kommunene og spesialiserte sykehusfunksjoner i ryggen. Veileder IS-1388. Oslo: Sosial- og helsedirektoratet, 2006.

10. Goldman HH, Skodol AE, Lave TR. Revising axis V for DSM-IV: a review of a measure of social functioning. Am J Psychiatry 1992; 149: 1148-56.

11. Wing J, Beevor A, Curtis RH et al. Health of the Nation Outcome Scales (HoNOS) Research and Development. Br J Psychiatry 1998; 172: 11-8.

12. Mueser KT, Drake RE, Clark RE et al. Evaluating substance abuse in persons with severe mental disorders. Concorde, $\mathrm{NH}$ : The Evaluation Center. Human Services Research Institute, 1995. http:// mentalhealth.samhsa.gov/cmhs/communitysupport/research/toolkits/pn6toc.asp (30.3.2009).

Manuskriptet ble mottatt 2.1. 2008 og godkjent 28.5. 2009. Medisinsk redaktør Erlend Hem. 